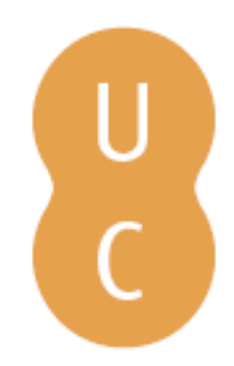

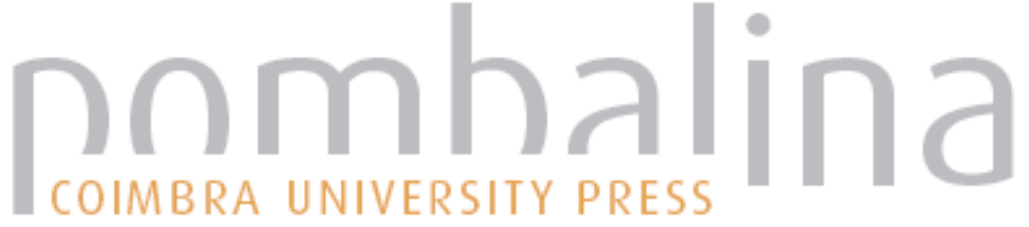

\section{O paradigma Darwiniano da história natural}
Autor(es):
Pereira, Ana Leonor
Publicado por: Imprensa da Universidade de Coimbra
URL persistente:
URI:http://hdl.handle.net/10316.2/31616
DOI:
DOI:http://dx.doi.org/10.14195/978-989-26-0199-1_19
Accessed : $\quad$ 26-Apr-2023 11:11:05

A navegação consulta e descarregamento dos títulos inseridos nas Bibliotecas Digitais UC Digitalis, UC Pombalina e UC Impactum, pressupõem a aceitação plena e sem reservas dos Termos e Condições de Uso destas Bibliotecas Digitais, disponíveis em https://digitalis.uc.pt/pt-pt/termos.

Conforme exposto nos referidos Termos e Condições de Uso, o descarregamento de títulos de acesso restrito requer uma licença válida de autorização devendo o utilizador aceder ao(s) documento(s) a partir de um endereço de IP da instituição detentora da supramencionada licença.

Ao utilizador é apenas permitido o descarregamento para uso pessoal, pelo que o emprego do(s) título(s) descarregado(s) para outro fim, designadamente comercial, carece de autorização do respetivo autor ou editor da obra.

Na medida em que todas as obras da UC Digitalis se encontram protegidas pelo Código do Direito de Autor e Direitos Conexos e demais legislação aplicável, toda a cópia, parcial ou total, deste documento, nos casos em que é legalmente admitida, deverá conter ou fazer-se acompanhar por este aviso.

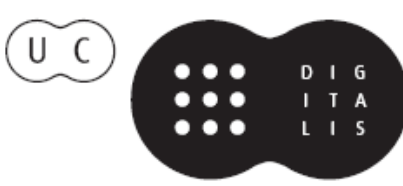


Maria Manuela Tavares Ribeiro

Coordenação

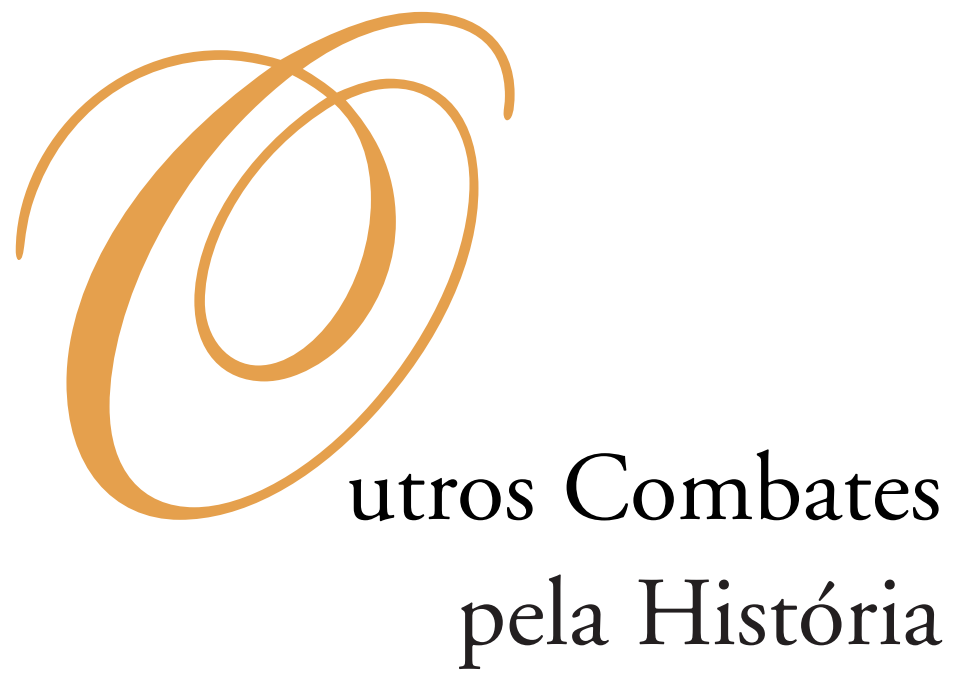




\section{COORDENAÇĀO EDITORIAL}

Imprensa da Universidade de Coimbra

Email: imprensauc@ci.uc.pt

URL: http://www.uc.pt/imprensa_uc

Vendas online: http://livrariadaimprensa.com

\section{CONCEPÇÃO GRÁFICA}

António Barros

\section{ORgANIZAÇĀO DOS TEXTOS}

Isabel Maria Luciano

Marlene Taveira

PRÉ-IMPRESSÃO

António Resende

Imprensa da Universidade de Coimbra

EXECUÇÃO GRÁFICA

SerSilito • Maia

ISBN

978-989-26-0041-3

DEPósito LEGAL

OBRA PUBLICADA COM O APOIO DE:

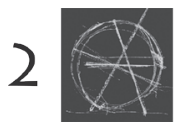

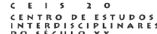

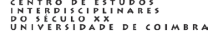

FCT Fundação para a Ciência e a Tecnologia

MINISTÉRIO DA CIÊNCIA, TECNOLOGIA E ENSINO SUPERIOR Portugal

Programa Operacional Ciência, Tecnologia, INOVAÇĀo DO QUADRo COMUNITÁRIO DE APOIO III

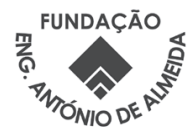

C JULHO 2010, IMPRENSA DA UNIVERSIDADE DE COIMBRA 
Maria Manuela Tavares Ribeiro

Coordenação

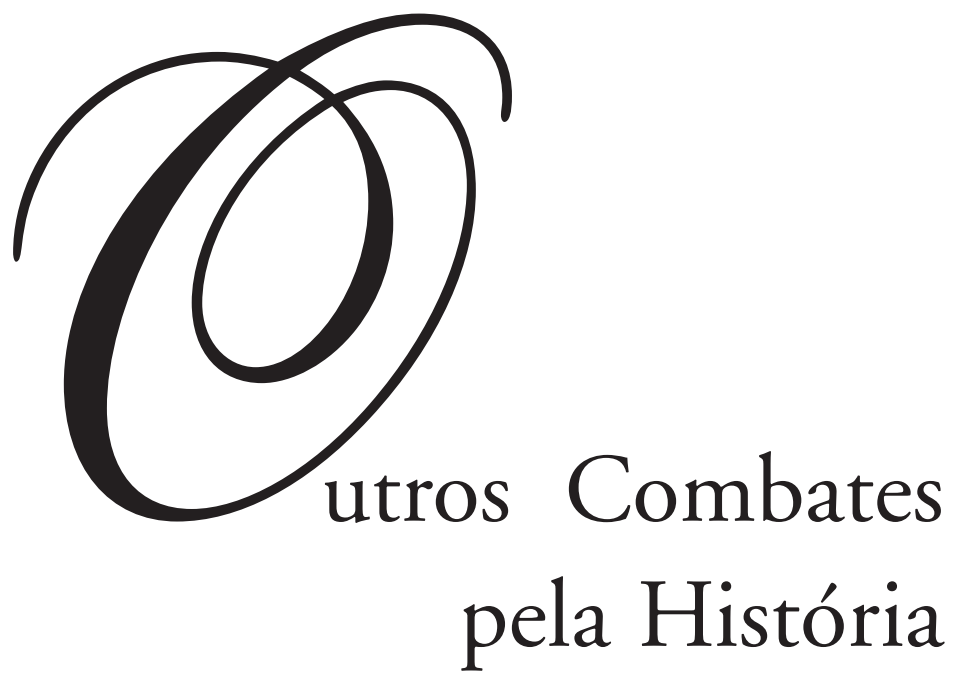

- colmbra 2010 
História e CiênCias 


\section{Ana Leonor Pereira}

\section{O PARADIGMA DARWINIANO DA HISTÓRIA NATURAL}

"the laws governing inheritance are for the most part unknown", The origin of species... Sixth edition, with additions and corrections.

London, John Murray, 1873, (edição definitiva) p. 10.

\section{Introdução à lógica darwiniana da vida}

Em qualquer parte do mundo, é voz corrente que o paradigma darwiniano da história natural defendido em 1859 é um paradigma inovador ${ }^{1}$ face à narrativa estática e teleológica da história natural ainda dominante, na época vitoriana. De facto, desde o dia 24 de Novembro de 1859 até aos dias de hoje de 2009, ano do duplo aniversário (200 anos do nascimento de Darwin e 150 anos da publicação da Origem das espécies), a nova lógica da vida construída pelo naturalista inglês conheceu uma história complexa, mas de sucesso, que reforçou a sua substância epistemológica. Recorrendo aos clássicos, diremos, em duas palavras, que a obra inaugural $O n$ the origin of species by means of natural selection, or the preservation of favoured races in the struggle for life, fez de Darwin o "Newton da biologia»" no sentido em que o «longo argumento» ${ }^{3}$ da sua teoria da «mutabilidade das espécies» ${ }^{4}$ revolucionou a ciência dos seres vivos.

\footnotetext{
1 Vide, entre centenas de catálogos, Darwin 200. 1809/2009, Catálogo de exposição, Viana do Castelo, C.M.I.A., 2009; A evolução de Darwin, Lisboa, Fundação Calouste Gulbenkian, 2009; John Van Wyhe, Darwin. The story of the man and his theories of evolution, Andre Deutsch, 2008.

2 Julian Huxley, O pensamento vivo de Darwin. Trad. e notas Paulo Sawaya. São Paulo, Livraria Martins, 1940, p. 20. Vide também: Michael Ruse, "Darwinism fleurit!», Isis, Chicago, 88(1) 1997, pp. 111-117; François Jacob; André Langaney, "Genèse et actualité de la théorie de l'évolution", La Recherche, Paris, 296, 1997, pp. 18-25.

3 "...this whole volume is one long argument...", Charles Darwin, On the origin of species by means of natural selection, or the preservation of favoured races in the struggle for life. (A reprint of the first edition). With a foreword by Dr. C. D. Darlington. London, Watts \& Co., 1950, p. 389.

4 "the mutability of species», Idem, ibidem, p. 409. Ou: "the theory of descent with modification", ibidem, p. 147; "the theory of natural selection", ibidem, p. 167; "the doctrine of the modification of species", ibidem, p. 409.
} 
Em termos historiográficos é assim: as autoridades já consagradas do domínio da história e da epistemologia das ciências da vida atribuem o estatuto de revolução científica $^{5}$ à teoria darwiniana. A justificação deste estatuto baseia-se, em vários argumentos, sobretudo no poder unificador da teoria, no seu «unificatory pattern» ${ }^{6}$, um critério que foi apresentado pelo próprio naturalista inglês, desde 1868, nos seguintes termos: «I believe in the truth of the theory, because it collects, under one point of view, and gives a rational explanation of many apparently independent classes of facts» ${ }^{7}$, tais como, a sucessão geológica dos seres organizados, a sua distribuição nos tempos passados e nos actuais, as suas afinidades mútuas e as suas homologias ${ }^{8}$. Por outro lado, a defesa do estatuto de revolução científica da teoria darwiniana implica a sua demarcação do fixismo essencialista e também do transformismo de Lamarck. Neste sentido, o clássico François Jacob, num livro marcante e inesgotável, dá corpo ao argumento segundo o qual a teoria darwiniana, textualmente, «n'est pas simplement le prolongement d'une pensée transformiste qui aurait commencé à s'exprimer avec Buffon et Lamarck. C'est l'effet d'un changement dans la manière même de considérer les objects, le résultat d'une attitude radicalement nouvelle qui apparaît au milieu du XIX ${ }^{\mathrm{e}}$ siècle»?

Darwin inaugurou um novo código de leitura da complexidade e da historicidade dos organismos vivos, irredutível ao mecanicismo ${ }^{10}$ ), ainda que a descendência com

\footnotetext{
5 Nalguns casos o termo revolução consta do título de trabalhos capitais neste domínio. Vide, entre outros, Gertrude Himmelfarb, Darwin and the darwinian revolution, London, Chatto \& Windus, 1959; John C. Greene, "O paradigma kuhniano e a revolução darwinista na história natural». In: História e Prática das Ciências, Lisboa, A Regra do Jogo Edições, 1979, pp. 117-150; John C. Greene, «La révolution darwinienne dans la science et la vision du monde». In: Nature, Histoire, Société. Essais en hommage à Jacques Roger, s.l., Klincksieck, 1995, pp. 79-97; Michael Ruse, La revolución darwinista (La ciencia al rojo vivo). Versión española de Carlos Castrodeza. Madrid, Alianza Editorial, 1983; D. R. Oldroyd, Darwinian impacts. An introduction to the darwinian revolution, Milton Keynes, The Open University Press, 1980; Denis Buican, La révolution de l'évolution. L'évolution de l'évolutionnisme, Paris, P.U.F., 1989; Patrick Tort, "La seconde révolution darwinienne». In: Darwinisme et société. Direction de Patrick Tort, Paris, Presses Universitaires de France, 1992, pp. 1-7; B. Continenza, «La teoria darwiniana tra evoluzione e rivoluzione». In: Guido Cimino; Bernardino Fantani, Le rivoluzioni nelle scienze della vita, Firenze, Leo S. Olschki Editore, 1995, pp. 109-126; Antonello La Vergata, "Che rivoluzione fu la rivoluzione darwiniana?». In: Guido Cimino; Bernardino Fantini, Le rivoluzioni nelle scienze della vita, ob. cit., pp. 101-108.

${ }^{6}$ Vide: Arthur L. Caplan, "The nature of darwinian explanation: is darwinian evolutionary theory scientific?», in: Laurie Rohde Godfrey, What Darwin began. Modern darwinian and non-darwinian perspectives on evolution. Edited by Laurie Rohde Godfrey. Boston e outras, Allyn and Bacon, 1985, pp. 24-35. À pergunta formulada, o autor responde positivamente: "when a theory manifests a unificatory pattern as powerful as that found in Darwinian theory's struggle for existence and natural selection, then scientists will go to great lengths (in the case of Darwinism a sustained effort of 125 years thus far) to preserve and defend the soundness of that basic pattern of explanation against apparent counter-examples, puzzles, and even empirical refutations», ibidem, p. 35. Itálico nosso.

7 Charles Darwin, The variation of animals and plants under domestication. (A reprint of the second editon, London, John Murray, 1885). Delhi, Daya Publishing House, 1989, vol. 1, pp. 13-14.

8 Vide: Idem, ibidem, vol. 1, p. 8 e ss.

${ }^{9}$ François Jacob, La logique du vivant. Une histoire de l'hérédité, Paris, Éditions Gallimard, 1970, p. 190.

${ }^{10}$ Vide: Marcello Cini, "Sciences galiléennes et sciences darwiniennes». In: Les pouvoirs de la science. Un siècle de prise de conscience, Paris, Librairie Philosophique J. Vrin, 1987, pp. 67-82.
} 
modificações se processe através de um mecanismo chave: a selecção natural. Mas, a selecção natural ${ }^{11}$, que preserva as variações individuais favoráveis ao processo adaptativo e elimina as variações nocivas, é um poder criador sem projecto apriorístico ${ }^{12}$ que «trabalha sobre variações não orientadas e muda a população, conferindo maior êxito reprodutivo às variantes vantajosas» ${ }^{13}$. Para acentuar a criatividade da selecção natural, os fundadores do neo-darwinismo contemporâneo ${ }^{14}$ traduziram-na metaforicamente. "A selecção natural [é] comparada a um compositor por Dobzhansky; a um poeta por Simpson; a um escultor por Mayr; e precisamente ao Sr. Shakespeare por Julian Huxley» ${ }^{15}$. Por seu turno, Stephen Jay Gould, o conceituado paleontólogo americano e historiador da teoria da evolução, co-autor do evolucionismo pontualista (punctuated equilibria) ${ }^{16}$, sublinha a justeza das referidas metáforas. À semelhança do músico, do poeta ou do escultor que dão forma às notas, às palavras e à pedra, também a selecção natural trabalha a partir de uma matéria prima, a variação individual, favorecendo a conservação e a disseminação das variações úteis e eliminando as nocivas ${ }^{17}$. A matéria prima não é apenas joeirada. Como acentuou François Jacob, as variaçôes são integradas e dispostas «em conjuntos adaptativamente coerentes, ajustados durante milhões de anos e milhões de geraçôes, em resposta ao desafio do meio ambiente. É a selecção natural que [...] lentamente, progressivamente, elabora estruturas cada vez mais complexas, órgãos novos, espécies novas» ${ }^{18}$. $\mathrm{Na}$ «bricolagem da evolução» ${ }^{19}$ ), os factores decisivos são a aleatoriedade das variações e a constante interacção dos organismos com o meio; este enunciado é simples, mas encerra os "atalhos sinuosos da contingência» ${ }^{20}$ que marca toda a história da vida. Assim sendo,

${ }^{11}$ A definição dada em 1859 é a seguinte: "this preservation of favorable variations and the rejection of injurious variations I call Natural Selection", Charles Darwin, On the origin of species by means of natural selection, or the preservation of favoured races in the struggle for life. (A reprint of the first editon), ob. cit., p. 70. Na edição definitiva lê-se: "this preservation of favorable individual differences and variations, and the destruction of those which are injurious, I have called Natural Selection, or the Survival of the Fittest", Charles Darwin, The origin of species by means of natural selection, or the preservation of favoured races in the struggle for life. Sixth edition, with additions and corrections. London, John Murray, 1873, p. 63.

${ }^{12}$ Vide o diagrama da árvore da vida construído por Charles Darwin, On the origin of species... (A reprint of the first editon), ob. cit., pp. 87-113.

13 Stephen Jay Gould, O polegar do panda. Reflexões sobre história natural, Lisboa, Gradiva, s. d., p. 87, sublinhado do Autor; vide também Charles Darwin, On the origin of species... (A reprint of the first edition), ob. cit., pp. 38-51.

14 Vide: Daniel Dreuil, «Néo-darwinisme. Neo-Darwinism». In: Dictionnaire du darwinisme et de l'évolution, vol. 2 (Dir. Patrick Tort), Paris, Presses Universitaires de France, 1996, pp. 3165-3184.

15 Stephen Jay Gould, O mundo depois de Darwin, Lisboa, Editorial Presença, 1988, p. 36.

16 Vide: Ana Leonor Pereira, "[Recensão crítica de] Stephen Jay Gould, O polegar do panda. Reflexões sobre história natural. Lisboa, Gradiva, s. d., 370 p.», Revista de História das Ideias, Coimbra, 12, 1990, pp. 471-476.

17 Cf. Stephen Jay Gould, O mundo depois de Darwin, ob. cit., p. 36 e ss.

18 François Jacob, O jogo dos possiveis. Ensaio sobre a diversidade do mundo vivo, Lisboa, Gradiva, 1985, p. 34 .

${ }^{19}$ Vide: Idem, ibidem, pp. 57-97.

20 Stephen Jay Gould, A vida é bela, Lisboa, Gradiva, s. d., p. 287. 
a teoria da descendência com modificações por selecção natural demarca-se também dos teleologismos vitalistas que caracterizam quer o fixismo essencialista tradicional quer o transformismo pretérito como o de Lamarck. No dizer de François Jacob «a concepção darwiniana tem, por isso, uma consequência fatal: o mundo vivo actual, tal como o vemos à nossa volta, é apenas um entre muitos possíveis. (...) Poderia muito bem ser diferente. Poderia mesmo não existir» ${ }^{21}$. Por seu turno, Stephen Jay Gould argumenta que a contingência é o selo da teoria darwiniana e não apenas um corolário $^{22}$ da mesma.

\section{A construção da teoria da descendência com modificaçôes por selecção natural}

A construção e, finalmente, a emergência da teoria darwiniana, em 1859, é um assunto inesgotável que, em nosso entender, ganha inteligibilidade no quadro dos modelos explicativos que se propõem ultrapassar a clássica distinção entre história (internalista e externalista) da ciência e filosofia da ciência ${ }^{23}$. Não é nosso propósito colocar todos os factores em rede e, nessa base, pretender alcançar a compreensão plena da revolução científica darwiniana. Visamos apenas assinalar, com o sentido crítico possível, alguns dos factores mais divulgados como tendo sido factores estruturantes ou desencadeantes da revolução darwiniana.

De acordo com Marjorie Grene ${ }^{24}$, a biografia de Darwin é insuficiente para explicar a revolução científica que o naturalista inglês operou, mesmo que ela seja iluminada por múltiplos factores, desde os geográficos aos sociais, além dos culturais e científicos. Todavia, como bem demonstrou Michael Ruse, a contextualização do autor e da sua obra tem o mérito de combater o mito do génio criador, isolado da comunidade científica do seu tempo ${ }^{25}$, concepção alimentada, sobretudo, pela perspectiva indutivista da criatividade científica. Com efeito, o aprofundamento dos contextos, intra e extra científicos, pode conduzir à reavaliação da célebre viagem do Beagle, tradicionalmente vista como a condição sine qua non da emergência da teoria darwiniana.

Assim sendo, é possível questionar se a viagem de circum-navegação feita por Darwin, a bordo do navio Beagle comandado pelo capitão Fitzroy, entre 1831 e $1836^{26}$,

21 ) François Jacob, O jogo dos possíveis. Ensaio sobre a diversidade do mundo vivo, ob. cit., pp. 34-35.

22 ) Vide: Stephen Jay Gould, A vida é bela, ob. cit., sobretudo p. 308.

23 ) Vide: a valiosa proposta de João Maria André, «Da história das ciências à filosofia da ciência. Elementos para um modelo ecológico do progresso científico", Revista Filosófica de Coimbra, Coimbra, 10, 1996, pp. 315-359.

24 ) Vide: Marjorie Grene, "Recent biographies of Darwin: the complexity of context», Perspectives on Science, Chicago, 1 (4), 1993, pp. 659-675.

25 ) Vide: Michael Ruse, La revolución darwinista (La ciencia al rojo vivo), ob. cit., pp. 53-58.

26 Vide: Charles Darwin, The voyage of the "Beagle». Journal of researches into the natural history and geology of the countries visited during the voyage round the world of H. M. S. "Beagle», London, The Amalgamated Press, 1905; Charles Darwin, Viagem de um naturalista ao redor do mundo. Trad. J. Carvalho. Rio de Janeiro, Cia. Brasil Editora, 1937; Jean Marc Drouin, «De Linné à Darwin: les voyageurs naturalistes». In: Michel Serres, Éléments d'histoire des sciences, Paris, Bordas, 1989, pp. 321-335; Alan Moorehead, Darwin. La expedición en el Beagle (1831-1836), Barcelona, Ediciones del Serbal, 1989. 
foi o acontecimento sine qua non que decidiu a carreira de Darwin e que, portanto, terá decidido o futuro das ciências da vida e do homem. Como é por todos bem sabido, durante 5 anos à volta do mundo no Beagle, Darwin fez pesquisas geológicas, coleccionou, sem restriçôes, volumes impressionantes de dados paleontológicos, botânicos, zoológicos e outros. Terá sido a observação desses factos, nomeadamente dos ossos dos mamíferos fósseis gigantes da América do Sul, das tartarugas e dos tentilhôes das Galápagos, da fauna marsupial da Austrália, etc., que gradualmente despertou o seu espírito para a ideia de descendência com modificações, como advoga, entre outros, Jorge Enrique Adoum 27.

É indiscutível que a viagem do Beagle foi crucial e que, tanto o contacto directo com a natureza, como a observação comparativa dos inúmeros testemunhos colectados impuseram na sua mente a dúvida em relação ao fixismo e, como argumenta Stephen Jay Gould, "destruiram a fé de Darwin na imutabilidade das espécies» ${ }^{28}$. De facto, data de finais da década de trinta do século XIX, o chamado «intervalo decisivo» ${ }^{29}$ ou o tempo de gestação da inovadora lógica da vida. Tanto quanto se sabe, o primeiro desenho darwiniano da árvore da vida data de 1837 e, em 1839, Darwin redigiu algumas notas da futura teoria da descendência com modificações e nelas estabelecia já o paralelo entre selecção natural e selecção artificial ${ }^{30}$. Posteriormente, em $1842^{31}$, Darwin faz o primeiro esboço da sua teoria e, em $1844^{32}$, escreve um longo manuscrito, cujo plano é praticamente idêntico à estrutura da obra de 1859 .

Algumas investigações sobre a revolução darwiniana combatem a sobrevalorização, quer da viagem do Beagle, quer da interacção directa do cientista com a natureza, alimentada pelo próprio Darwin ${ }^{33}$, e trazem para primeiro plano os factores contextuais, sobretudo, intra-científicos. Assim, defende-se que foi o extraordinário desenvolvimento da biologia ${ }^{34}$ entre 1838 e 1859 (estudos embriológicos, estudos das estruturas orgânicas, do registo fóssil, da distribuição geográfica e outros) que possibilitou a

27 Vide: Jorge Enrique Adoum, «Les Galapagos. L'origine de l'origine», Le Courrier de l'Unesco, Paris, 35 5) Maio 1982, pp. 24-28.

28 Stephen Jay Gould, $O$ mundo depois de Darwin, ob. cit., p. 17.

29 Vide: Germano da Fonseca Sacarrão, «Apontamentos sobre o darwinismo», Naturália, Lisboa, nov. sér., (2) Jan. 1982, pp. 30-32; (3) Maio 1982, p. 29.

30 Vide: Daniel Becquemont, «Introduction». In: Charles Darwin, Ébauche de l'origine des espèces (Essai de 1844). Traduction de Charles Lameere, revue, complétée et annotée par Daniel Becquemont. Lille, Presses Universitaires de Lille, 1992, p. 7.

31 Vide: Charles Darwin, The foundations of the origin of species, a sketch written in 1842. Edited by his son Francis Darwin. Cambridge, Printed at the University Press, 1909.

32 Apenas pudemos consultar a edição francesa, Charles Darwin, Ébauche de l'origine des espèces (Essai de 1844), ob. cit..

33 Vide: Charles Darwin, On the origin of species... (A reprint of the first editon), ob. cit., pp. 1-5; Idem, The variation of animals and plants under domestication. (A reprint of the second editon, London, John Murray, 1885), ob. cit., vol. 1, p. 9 e ss.

34 Recorde-se que o termo biologia foi criado simultaneamente por Lamarck em França e por Treviranus na Alemanha em 1802. Vide Maurice Caullery, Les étapes de la biologie. Nouvelle édition par le Dr. Jean Torlais. Paris, Presses Universitaires de France, 1964, p. 43. 
emergência do novo paradigma ${ }^{35}$. Neste sentido, também Daniel Becquemont valoriza a investigação científica em curso na época, feita no quadro do fixismo e desvaloriza a ideia dos precursores de Darwin, especialmente do avô Erasmo Darwin e de Lamarck. De acordo com o autor, «Darwin doit bien plus aux recherches de ses contemporains 'fixistes' (anatomie comparée, embryologie, paléontologie, classification, distribution géographique) qu'aux premiers évolutionnistes que sont Lamarck et Erasmus Darwin» ${ }^{36}$. $\mathrm{Na}$ verdade, é questionável que as especulações transformistas do médico, poeta e botânico Erasmus Darwin ${ }^{37}$ (avô paterno de Charles Darwin) e de Lamarck, na sua Philosophie Zoologique (1809) ${ }^{38}$, pressupondo a harmonia do universo e a hierarquia dos seres, tenham sido fonte inspiradora para um modelo tão diferente como é o paradigma darwiniano da história natural.

Na teoria lamarckiana, os organismos são detentores de uma capacidade de adaptação ao meio que garante a regularidade da progressão dos mesmos, em harmonia com as condiçôes mesológicas ${ }^{39}$. Diferentemente, Darwin constata a luta dos seres vivos entre si, pelo território, pelo alimento, pela descendência, sendo a sobrevivência dos mais aptos (selecção natural), isto é, daqueles que apresentam variações úteis e vantajosas, o alicerce da diferenciação genealógica por divergência e isolamento ${ }^{40}$. Na teoria lamarckiana, a progressão é contínua e harmoniosa e não se baseia em qualquer conflitualidade. Segundo François Jacob, «il n’y a jamais de crise entre les êtres et la nature, aucun combat pour la conquête d'un territoire entre les êtres eux-mêmes» ${ }^{41}$.

35 Vide: Dov Ospovat, The development of Darwin's theory. Natural history, natural theology, and natural selection, 1838-1859, Cambridge, University Press, 1995.

36 Daniel Becquemont, Darwin, darwinisme, évolutionnisme, Paris, Ed. Kimé, 1992, p. 12. Vide também Thomas S. Kuhn, A tensão essencial, Lisboa, Edições 70, 1989, p. 180 e ss.

37 A influência da Zoonomia (1794-1796) de Erasmus Darwin no transformismo lamarckiano e na teoria da descendência com modificações de Charles Darwin é admissível, mas difícil de precisar como informa Pietro Omodeo no artigo "Darwin, Erasmus 1731-1802». In: Dictionnaire du darwinisme et de l'évolution, vol. 1, ob. cit., pp. 812-815. Algumas obras capitais de Erasmus Darwin foram traduzidas para português. Por exemplo: O jardim botanico de Darwin. Ou a economia da vegetação, poema com notas filosoficas, traduzido do inglez por Vicente Pedro Nolasco da Cunha, Lisboa, Na Regia Officina Typografica, 1803-1804. Na Academia das Ciências de Lisboa existem os seguintes manuscritos: Phytologia, ou philosophia da agricultura e horticultura, ou compendio de geurgia e phyturgia philosophicas, por Erasmo Darwin, doutor em medicina, e da Sociedade Real de Londres, etc., em 1800. Traduzida em portuguez [por Felix Avellar Brotero], 3 vols. (142, 248, 175 pp.). Ms. 361-363; Zoonomia ou as leis da vida organica. Traduzida do original inglez em portuguez. Terceira edição corrigida. Derby, 1805 - Manuscrito de 147 pp.. Ms. 379.

38 Consultámos a seguinte edição: Jean Baptiste Lamarck, Philosophie zoologique ou exposition des considérations relatives à l'histoire naturelle des animaux. (...). Nouvelle édition revue et précédée d'une introduction biographique par Charles Martins. Paris, Librairie F. Savy, 1873, 2 vols.. Sobre a teoria lamarckiana, vide, nomeadamente: A. de Quatrefages, Charles Darwin et ses précurseurs français. Étude sur le transformisme, Paris, Germer Baillière, 1870, pp. 42-59; M.J.S. Hodge, «Lamarck: un grand changement de cadre conceptuel». In: Nature, Histoire, Société. Essais en hommage à Jacques Roger, s.l., Klincksieck, 1995, pp. 229-239.

39 Vide: Jean Baptiste Lamarck, Philosophie zoologique... ob. cit., vol. 1, sobretudo pp. 71-347. Idem, Articles d'histoire naturelle, Paris, Éditions Belin, 1991, pp. 78-88.

40 Vide: Charles Darwin, On the origin of species... (A reprint of the first editon), ob. cit., sobretudo pp. 87 e ss.

${ }^{41}$ François Jacob, La logique du vivant. Une histoire de l'hérédité, ob. cit., p. 165. Vide também André Langaney, "Fugue à deux voix pour une théorie», Les cahiers de science \& vie, Paris, 6, 1991, pp. 6-18. 
Também Stephen Jay Gould concluiu que, em Lamarck, «a variação é dirigida automaticamente para a adaptação e nenhuma segunda força como a selecção natural é necessária» ${ }^{42}$. Em duas palavras, dizemos com François Jacob que, na perspectiva lamarckiana, «le monde vivant n'est pas seulement le meilleur, mais le seul possible» ${ }^{43}$. Pelo contrário, no paradigma darwiniano, o mundo vivo não traz as marcas da necessidade e da harmonia perfectibilista ${ }^{44}$, mas da aleatoriedade, da contingência, da imprevisibilidade, da imperfeição e do improviso ${ }^{45}$. Conforme argumenta Stephen Jay Gould, «Darwin reconheceu que a perfeição não pode fazer prova da evolução, porque a optimização oculta os trilhos da história» ${ }^{46}$. A optimização ou perfeita adaptação, (como no caso da perfeição aerodinâmica de uma pena) tem um poder demonstrativo da descendência com modificaçôes muito limitado. Pelo contrário, as imperfeiçôes, como o improvisado «polegar» do panda gigante que se desenvolveu a partir do osso sesamóide radial do pulso ${ }^{47}$, as estruturas vestigiais ou rudimentares, os remanescentes, como o apêndice humano, etc., constituem argumentos excelentes da teoria darwiniana. No dizer de Stephen Jay Gould: «Darwin reconheceu que a prova irrefutável da evolução deve ser procurada nos desvios, nas estranhezas e nas imperfeiçôes que jazem nos trilhos da história» 48 . Por isso, Darwin concluiu: «the wonder indeed is, on the theory of natural selection, that more cases of the want of absolute perfection have not been observed ${ }^{49}$.

Meio século depois da Philosphie Zoologique de Lamarck, o estado da arte faz nascer a ideia de contingência da vida, uma ideia estranha ao criacionismo essencialista mas também ao transformismo lamarckiano. Neste sentido, François Jacob sublinha que «les documents paléontologiques, la distribution géographique des espèces, le développement des embryons, les phénomènes de divergence des caractères à partir d'un ancêtre commun, l'extension de certains groupes et la disparition de certains autres, tout concourt à montrer la contingence des êtres vivants et de leur formation» 50 . $\mathrm{Na}$ base desta argumentação, pode dizer-se que foram os progressos realizados pelas

42 Stephen Jay Gould, O polegar do panda. Reflexões sobre história natural, ob. cit., pp. 88-89.

43 François Jacob, La logique du vivant. Une histoire de l'hérédité, ob. cit., p. 165.

${ }^{44}$ Esta é também a conclusão a que chegou a conceituada especialista Yvette Conry, como é notório neste resumo condensado: «la biologie darwinienne ne définit plus la vie par une tendance à la progression par la différenciation, mais par une capacité aux variations supportées par des organismes dont la spécificité réside précisément dans une différence aléatoire, celle-ci ne se typifiant à échelle de générations que par l'écart croissant dû à l'accumulation des minima différentiels et à l'éviction des déshérités", in: L'introduction du darwinisme en France au XIX siècle, Paris, Librairie Philosophique J. Vrin, 1974, p. 218.

45 Vide: François Jacob, La logique du vivant. Une histoire de l'hérédité, ob. cit., sobretudo p. 190. Vide, também, Goulven Laurent, "Darwin ou l'héritage refusé», Les cahiers de science \& vie, Paris, 6, 1991, pp. 34-50.

46 Stephen Jay Gould, A vida é bela, ob. cit., p. 308.

47 Vide: Ana Leonor Pereira, «[Recensão crítica de] Stephen Jay Gould, O polegar do panda. Reflexōes sobre história natural. Lisboa, Gradiva, s. d., 370 p.», art. cit., pp. 471-476.

48 Stephen Jay Gould, A vida é bela, ob. cit., p. 308.

49 Charles Darwin, On the origin of species... (A reprint of the first editon), ob. cit., p. 400. Vide também Idem, ibidem, pp. 147-177.

${ }^{50}$ François Jacob, La logique du vivant. Une histoire de l'hérédité, ob. cit., p. 183. 
ciências da terra e da vida, na primeira metade do século XIX, que possibilitaram «a revolução bem sucedida de Darwin», e que permitem compreender a «revolução falhada de Lamarck» ${ }^{51}$, para utilizar as expressões de John Greene.

Os avanços da geologia e de várias disciplinas biológicas, nas décadas de 30, 40 e 50 do século XIX, não explicam tudo, como é obvio. Além disso, a comunidade científica internacional não mostrava sinais de uma "psicologia de crise» 52 , relativamente ao denominado paradigma estático da história natural ${ }^{53}$. No termo da década de cinquenta do século XIX, os naturalistas europeus «são quase todos mais ou menos criacionistas" 54 .

É sintomático que o único naturalista britânico que antes de Darwin publicou uma teoria geral de tipo evolucionista, o tenha feito anonimamente. Com efeito, o naturalista e editor escocês, Robert Chambers ${ }^{55}$ publicou em Londres, em 1844, uma obra intitulada Vestiges of the natural history of Creation, alicerçada em grande parte no evolucionismo cósmico da Naturphilosophie germânica ${ }^{56}$ e no transformismo de Étienne Geoffroy Saint-Hilaire ${ }^{57}$. Esta obra foi alvo de críticas reprovatórias, quer por parte da opinião pública letrada, quer por parte dos especialistas, e não conseguiu abrir alguma brecha consistente no paradigma estático da história natural.

A reacção negativa da comunidade científica internacional à obra de $\mathrm{R}$. Chambers reforçou a prudência de Darwin. De facto, em 1844, data da publicação de Chambers, a teoria da descendência com modificações encontrava-se perfeitamente esboçada; mas, só seria publicada quinze anos depois 58 , sob o efeito do stress provocado pela leitura do trabalho inédito que, em 1858, o naturalista A. R. Wallace enviara a Darwin do arquipélago malásio, onde fazia exploraçōes desde 1854, continuadas até $1862^{59}$.

51 John C. Greene, "O paradigma kuhniano e a revolução darwinista na história natural», art. cit., p. 136. Sublinhado do Autor.

52 Idem, ibidem, p. 141.

53 Vide: Idem, ibidem, sobretudo p. 131 e ss. Houve, no entanto, algumas controvérsias, como o famoso debate em França entre Étienne Geoffroy Saint-Hilaire e Georges Cuvier em 1830 na Academia Real das Ciências. Sobre o assunto, vide, Hervé Le Guyader, "Geoffroy Saint-Hilaire, Étienne 1772-1844, et Cuvier, Georges 1769-1832. Débat». In: Dictionnaire du darwinisme et de l'évolution, vol. 2, ob. cit., pp. 1867-1883; Paul Pelseneer, "Os primeiros tempos da ideia evolucionista: Lamarck, Geoffroy Saint-Hilaire e Cuvier», Jornal de Sciencias Naturaes, Lisboa, 2 (1) Jan.-Mar. 1922, pp. 1-11.

54 Émile Nöel, O Darwinismo hoje, Lisboa, Publicaçōes Dom Quixote, 1981, p. 11.

55 Vide: Mario Di Gregorio, "Chambers, Robert 1802-1871». In: Dictionnaire du darwinisme et de l'évolution, vol. 1, ob. cit., pp. 566-567.

56 Recorde-se que a Naturphilosophie foi inaugurada por J.W. von Goethe, o filósofo Schelling e os cientistas Oken e Kielmeyer, entre outros, em fins do século XVIII e princípio do século XIX. Vide "Naturphilosophie», in: MacMillan dictionary of the history of science. Edited by W. F. Bynum, E. J. Browne, Roy Porter. London-Basingstoke, MacMillan Reference Books, 1983, pp. 292-293; Erik Nordenskiöld, The history of biology. A survey, London, Kegan Paul, Trench, Trubner \& Co., 1929, pp. 273 e ss.

57 Sobre o transformismo de Étienne Geoffroy Saint-Hilaire, vide A. de Quatrefages, Charles Darwin et ses précurseurs français. Étude sur le transformisme, ob. cit., p. 60 e ss.

58 Vide: Michael Ruse, La revolución darwinista (La ciencia al rojo vivo), ob. cit., pp. 234-239; Stephen Jay Gould, O mundo depois de Darwin, ob. cit., pp. 17-22.

59 Vide: Gérard Molina, "Wallace, Alfred Russel 1823-1913». In: Dictionnaire du darwinisme et de l'évolution, vol. 3, ob. cit., pp. 4565-4586. 
O trabalho de Walllace intitulava-se $O n$ the tendency of varieties to depart indefinitely from the original type ${ }^{60}$ e nele Darwin viu estampada uma teoria semelhante à sua teoria da descendência com modificações por selecção natural.

No seu estudo bem fundamentado, Gerhard Wichler concluiu que, até 1859, a hipótese da criação das espécies, da constância e imutabilidade das mesmas, estava firmemente instalada, sendo Cuvier a grande autoridade de referência ${ }^{61}$. Fundador da paleontologia dos vertebrados ${ }^{62}$ e autoridade máxima em anatomia comparada, Cuvier deu a conhecer mais de cento e cinquenta espécies fósseis de vertebrados ${ }^{63}$, entre as quais monstros célebres como o megatherium, o ichthyosaurus e o plesiosaurus. $\mathrm{Na}$ verdade, Cuvier sabia decifrar os esqueletos a partir de um único fragmento ósseo. $\mathrm{Na}$ base do princípio da correlação das formas nos seres organizados e de outras regras, Cuvier dominava a arte "de reconnaître un genre, et de distinguer une espèce par un seul fragment d'os» 64 . De acordo com a sua leitura catastrofista da história da terra conjugada com o fixismo das espécies, Cuvier defendia que os seres que se sucederam na superfície do globo no decurso dos tempos geológicos, não apresentavam entre si qualquer relação de descendência. De cada vez que o globo terrestre sofreu uma revolução súbita e instantânea, os seres vivos que nele habitavam extinguiram-se por destruição. Por isso, em seu entender, «les espèces perdues ne sont pas des variétés des espèces vivantes» ${ }^{65}$. A cada revolução do globo correspondia a destruição das espécies então existentes, tendo a última revolução ocorrido há cinco ou seis mil anos ${ }^{66}$. Por isso, nos arquivos da terra faltavam as formas intermediárias, isto é, testemunhos fósseis de modificações graduais. Com este argumento perturbador ${ }^{67}$, Cuvier desautorizava o anti-catastrofismo e o transformismo de Lamarck. De facto, o paradigma

60 Este texto foi publicado no Journal of the Proceedings of the Linnean Society, Agosto de $1858 \mathrm{e}$ reproduzido em The Darwin-Wallace celebration held on thursday, 1st July, 1908, London, Linnean Society of London, 1908, pp. 98-107. Foi divulgado em francês, nomeadamente na colectânea de Alfred Russell Wallace, La sélection naturelle. Essais. Traduits de l'anglais sur la deuxième édition avec l'autorisation de l'auteur par Lucien de Candolle. Paris, C. Reinwald et Cie., Libraires-Éditeurs, 1872, pp. 28-44.

61 Vide: Gerhard Wichler, Charles Darwin. The founder of the theory of evolution and natural selection, Oxford e outras, Pergamon Press, 1961, pp. 69-77.

62 A obra de Georges Cuvier, Recherches sur les ossemens fossiles de Quadrupèdes, publicada em 1812, é considerada como sendo fundadora da paleontologia dos vertebrados. Vide: Goulven Laurent, «Paléontologie (Darwin et la), Palaeontology (Darwin and)». In: Dictionnaire du darwinisme et de l'évolution, vol. 3, ob. cit., pp. 3329-3335.

63 Vide: Georges Cuvier, Discours sur les révolutions du globe. Avec des notes et un appendice d'après les travaux récents de Mm. De Humboldt, Flourens, Lyell, Lindley, etc. rédigés par le Dr. Hoefer, Paris, Librairie de Firmin Didot Frères, Fils et $\mathrm{C}^{\mathrm{ie}}$., 1867, sobretudo p. 40 e ss; p. 70. O Discours, publicado pela primeira vez em 1812 como introdução a Recherches sur les ossemens fossiles (...) foi trazido em português: Discurso sobre as revoluçôes da superficie do globo e sobre as mudanças que ellas occasionaram no reino animal. Traduzida da sexta edição franceza em 1832 por Francisco Ferreira de Abreu. Lisboa, Imprensa Nacional, 1872.

${ }^{64}$ Georges Cuvier, Discours sur les révolutions du globe, ob. cit., p. 3.

65 Idem, ibidem, p. 77.

66 Idem, ibidem, pp. 177-178.

67 Atente-se no argumento de Cuvier: «Pourquoi les entrailles de la terre n’ont-elles point conservé les monuments d'une généalogie si curieuse, si ce n'est parce que les espèces d'autrefois étaient aussi constantes que les nôtres, ou du moins parce que la catastrophe qui les a détruites ne leur a pas laissé le temps de se 
estático da história natural era acolhido pela comunidade científica internacional, inclusive pelos maiores amigos de Darwin, o geólogo Charles Lyell, os botanistas Joseph Hooker e Asa Gray e o zoólogo Thomas A. Huxley ${ }^{68}$.

No entanto, Charles Lyell, nos seus Principles of geology (1830-1832), defendia a doutrina das "causas actuais", actualismo ou uniformitarismo, segundo a qual as causas que hoje produzem mudanças mínimas, regulares e contínuas na superfície da terra são as mesmas que provocaram as mudanças outrora ocorridas ${ }^{69}$. A história da terra não é feita de "catastrophes subites, violentes et générales» ${ }^{70}$ como pretendia Cuvier. O tempo geológico é uniforme e a evolução lenta e progressiva da face da terra resulta da acção de constantes agentes naturais que, em todos os períodos geológicos, produzem efeitos idênticos ${ }^{71}$. Apesar do seu uniformitarismo geológico, Lyell não aceitava a teoria transformista no mundo orgânico, tendo permanecido fixista até à revolução darwiniana em 1859 . Nos seus Principles of geology, a teoria lamarckiana era longamente exposta e refutada ${ }^{72}$, o que pode ser tomado como mais um indicativo da vigência do paradigma estático até $1859^{73}$.

A obra geológica de Lyell foi uma peça fundamental na elaboração da teoria darwiniana, o que é notório na Origem das Espécies e foi sublinhado pelo próprio Darwin na sua autobiografia ${ }^{74}$. De resto, a construção da teoria da descendência com modificações seria impensável se Darwin não possuísse um bom nível de conhecimentos geológicos. Na Universidade de Edimburgo, que frequentou entre 1825 e 1827 ,

livrer à leurs variations?», Discours sur les révolutions du globe, ob. cit., p. 78. Vide também o artigo «missing link", MacMillan dictionary of the history of science, ob. cit., p. 272.

68 Vide: Gerhard Wichler, Charles Darwin. The founder of the theory of evolution and natural selection, ob. cit., p. 204 e ss. Depois de 1859, Thomas Huxley tornou-se o grande defensor público de Darwin e Asa Gray foi o pioneiro da teoria da descendência na América. Joseph Hooker e Charles Lyell também adoptaram o evolucionismo biológico. Mas é de salientar que cada um destes grandes cientistas construiu a sua versão da nova teoria.

69 Sobre o uniformitarismo de Charles Lyell, vide Geof Bowker, «Les origines de l'uniformitarisme de Lyell: pour une nouvelle géologie». In: Michel Serres, Éléments d'histoire des sciences. Paris, Bordas, 1989, pp. 387-405.

${ }^{70}$ Charles Lyell, Principes de géologie ou illustrations de cette science empruntées aux changements modernes que la terre et ses habitants ont subis. Ouvrage traduit de l'anglais sur la sixième édition, et sous les auspices de M. Arago, par Mme Tullia Meulien. Paris, Langlois et Leclercq, 1843, vol. 1, p. XVI; sobre a refutação das revoluções súbitas na história da terra, vide, Idem, ibidem, p. 445 e ss.

${ }^{71}$ Vide: Geof Bowker, «Les origines de l'uniformitarisme de Lyell: pour une nouvelle géologie», art. cit., pp. 387-405; R. Furon, «La géologie». In: Histoire générale des sciences. Publiée sous la direction de René Taton. Tome III. vol. I - Le XIX e siècle. Paris, Presses Universitaires de France, 1981, pp. 371-392.

72 Charles Lyell, Principes de géologie... ob. cit., vol. 1, 1843, pp. 360-415; Idem, ibidem, vol. 4, 1848, pp. $1-130$.

${ }^{73}$ Nas edições dos Principles of geology posteriores a 1859, Lyell expõe a teoria darwiniana, sem discordar dos seus traços fundamentais. Consultámos Charles Lyell, Principes de géologie ou illustrations de cette science empruntées aux changements modernes de la terre et de ses habitants. Ouvrage traduit sur la dernière édition anglaise, entièrement refondue, (...), par M. J. Ginestou. Paris, Garnier Frères, 1873, vol. 2, pp. 403-418.

${ }^{74}$ Charles Darwin, Memorias y epistolario intimo. Mi vida-Recuerdos del hijo-Correspondencia selecta. Prólogo de Alberto Palcos. Buenos Aires, Editorial Elevación, 1946, p. 165 e ss.; vide também Michael Ruse, La revolución darwinista (La ciencia al rojo vivo), ob. cit., pp. 73-82. 
e onde era suposto estudar medicina, por decisão paterna, Darwin dedicou-se à geologia e o mesmo ocorreu na Universidade de Cambridge entre 1828 e 1831 onde alcançou o diploma de "Bachelor of Arts». Pode dizer-se que, em Cambridge, onde estudou teologia como lhe determinara o considerado médico Robert Waring Darwin, seu pai, o jovem Charles dava, sobretudo, livre curso à sua vocação genuína ${ }^{75}$. Durante a viagem do Beagle (1831-1836), Darwin leu e estudou os Principles of geology de Lyell ${ }^{76}$ o que, a par das pesquisas feitas no terreno, de geologia 77 , biogeografia e ecologia, foi determinante para a emergência da teoria da descendência com modificações. No entanto, a relação entre o uniformitarismo geológico e o evolucionismo biológico não era uma relação necessária como demonstrou Reyer Hooykaas ${ }^{78}$ e, assim sendo, pode dizer-se que, em última análise, a teoria de Darwin ${ }^{79}$ vem dele próprio, da sua inteligência, da sua consciência da inadequação do paradigma estático da biologia aos múltiplos dados científicos, avançados a partir dos anos trinta do século XIX. A sua intelecção do esgotamento do paradigma estático da história natural é uma das expressōes da sua genialidade.

A par dessa consciência do esgotamento do fixismo essencialista, Darwin tinha a convicção de que a comunidade científica não estava preparada para aceitar o novo paradigma e também não lhe parecia que o público em geral esperasse a queda do criacionismo fixista ${ }^{80}$. A verdade, porém, é que o dia 24 de novembro de 1859 mostrou algo muito interessante. Como é bem sabido, a Origem das espécies alcançou um êxito editorial imediato. Darwin reflectiu sobre o surpreendente sucesso da sua obra: 1.250 exemplares esgotados em 24 de Novembro de 1859; mais 3.000 exemplares em 1860 , na segunda edição; até 1876 , só em Inglaterra, havia 16.000 exemplares vendidos ${ }^{81}$.

75 Vide: James A. Secord, "The discovery of a vocation: Darwin's early geology», The British Journal for the History of Science, London, 24 (2-81) Jun. 1991, pp. 133-157. Frank H. T. Rodhes, «Darwin's search for a theory of the earth; symmetry, simplicity and speculation", The British Jounal for the History of Science, London, 24 (2-81) Jun. 1991, pp. 193-229.

76 Vide: Michael T. Ghiselin, «Darwin, Charles Robert 1809-1882». In: Dictionnaire du darwinisme et de l'évolution, vol. 1, ob. cit., sobretudo p. 774.

77 Vide: Sandra Herbert, "Charles Darwin as a prospective geological author», The British Journal for the History of Science, London, 24 (2-81) Jun. 1991, pp. 159-192.

78 Reyer Hooykaas, "The parallel between the history of the earth and the history of the animal world»; "Geological uniformitarianism and evolution». In: Selected studies in history of science, Coimbra, Por Ordem da Universidade, 1983, respectivamente pp. 447-466; pp. 467-488.

79 Está fora de questão, como escreveu Reyer Hooykaas, que «Darwin borrowed from Lyell the idea of slow and imperceptibly small changes adding up to larger transformations in the course of very long periods", "Catastrophism in geology, its scientific character in relation to actualism and uniformitarianism". In: Selected studies in history of science, ob. cit., p. 556.

80 Vide: Charles Darwin, Memorias y epistolario intimo... ob. cit., p. 85 e ss.

${ }^{81}$ Cf. Charles Darwin, Memorias y epistolario intimo... ob. cit., p. 84. Os números referidos coincidem com os dados da investigação de R. B. Freeman, The works of Charles Darwin. An annotated bibliographical handlist. Second edition revised and enlarged. Folkestone-Hamden, Dawson-Archon Books, 1977, pp. 84-87. Comparando com as tiragens de algumas obras literárias, os números referidos não são muito elevados. Mas, tratando-se de uma obra científica, a tiragem foi, de facto, excepcional. Vide: Gertrude Himmelfarb, Darwin and the darwinian revolution, ob. cit., p. 209. 
No entanto, Darwin justificava um tal sucesso com uma razão simples: a Origem das espécies era um volume pequeno (cerca de 420 páginas) escrito em 13 meses e 10 dias que abreviava selectivamente um longo manuscrito começado em $1856^{82}$.

Recorde-se que, para assegurar a Darwin os direitos de prioridade na descoberta da teoria seleccionista, Lyell e Hooker apresentaram em 1 de Julho de 1858 à Linnean Society of London o artigo de Wallace, já referido, precedido de excertos de manuscritos de Darwin datados de 1844 e de $1857^{83}$. Compreende-se que, pela força destas circunstâncias, a Origem das espécies tinha de vir a lume, num prazo limitado. Foi o que sucedeu e a obra não é assim tão pequena comparada com ouras obras científicas da época. Por isso, a reflexão de Darwin sobre o sucesso da sua obra pouco adianta. Claro que em 1859, o naturalista inglês já era conhecido do público, sobretudo pelas suas publicaçôes respeitantes às pesquisas realizadas na viagem do Beagle; além disso, também gozava de prestígio no seio da Linnean Society of London e da comunidade científica internacional, nas áreas de geologia e de sistemática zoológica ${ }^{84}$. No entanto, este prestígio do naturalista também não explica o sucesso de vendas da Origem das espécies.

\section{A teoria da selecção naural, a matemática malthusiana e a luta pela vida de outros memes}

A perspectiva sociologista baseada no argumento de Marx e de Engels, segundo o qual a teoria da selecção natural espelha a lógica económica e social da Inglaterra vitoriana, talvez adiante algo sobre o sucesso da obra de 1859 . Recorde-se que em carta dirigida a Engels, datada de 18 de Junho de 1862, Marx avaliou a teoria darwiniana nestes termos: «(...) Darwin reconnaît chez les animaux et les plantes sa propre société anglaise, avec sa division du travail, sa concurrence, ses ouvertures de nouveaux marchés, ses 'inventions' et sa malthusienne 'lutte pour la vie'. C'est le bellum omnium contra omnes de Hobbes (...)»85. A mesma interpretação da teoria darwiniana enquanto doutrina burguesa é emitida posteriormente, tanto por Marx (carta a Laura e Paul Lafargue, Londres, 15 de Fevereiro de 1869) como por Engels (carta a Piotr Lavrov, Londres 12-17 de Novembro de 1875) ${ }^{86}$. Sem dúvida, qualquer teoria científica ou outra é construída num contexto histórico e é ela mesma histórica ${ }^{87}$. Mas, de que

82 Vide: Idem, ibidem, p. 82 e ss.

83 Os textos originais de Darwin e de Wallace foram reeditados em The Darwin-Wallace celebration held on thursday, 1st July, 1908, London, Linnean Society of London, 1908, pp. 87-107. Devido ao excepcional carácter, tanto de Darwin como de Wallace, o seu relacionamento continuou a ser bom, independentemente das posteriores divergências teóricas. Vide o elucidativo artigo de Ralph Colp, "I will gladly do my best'. How Charles Darwin obtained a civil list pension for Alfred Russel Wallace», Isis, Philadelphia, 83 (1) Mar. 1992, pp. 3-26.

84 Vide: Michael Ruse, La revolución darwinista (La ciencia al rojo vivo),ob. cit., p. 315 e ss.

85 Karl Marx; Friedrich Engels, Lettres sur les sciences de la nature (et les mathèmatiques). Traduction et introduction de Jean-Pierre Lefebvre. Paris, Éditions Sociales, 1974, p. 21.

86 Cf. Idem, ibidem, p. 70 e p. 85 , respectivamente.

87 Sobre as implicações deste enunciado pacífico vide Gérard Fourez, La construction des sciences. Les logiques des inventions scientifiques. Introduction à la philosophie et à l'éthique des sciences. Deuxième édition revue, s. 1., De Boeck Université, 1992; Georges Canguilhem, Ideologia e racionalidade nas ciências da vida, 
modo o texto reflecte o contexto? Em que medida os contextos explicam o texto e, como no caso da Origem das espécies, o seu sucesso?

É perfeitamente pacífico aceitar que a construção da teoria da selecção natural e a sua afirmação pública tornam-se mais compreensíveis à luz do ambiente familiar e social, bem como da trajectória intelectual do seu autor. Darwin cresceu num nicho familiar marcado pela conjugação do espírito liberal tendencialmente agnóstico ${ }^{88}$, do lado do pai e do avô paterno, com o espírito industrialista do lado materno, afirmado de modo singular na cerâmica, a famosa faiança artística de Wedgwood ${ }^{89}$. Além da cultura (desde a cultura religiosa à cultura empresarial passando pela cultura médica e científica) e da fortuna herdadas, também é inegável que Charles Darwin leu, a título de distração do seu labor científico, algumas obras de economia e de demografia no verão de 1838, designadamente de A. Smith ${ }^{90}$ e, sobretudo, de Malthus ${ }^{91}$. Mas, em que medida a leitura darwiniana do Essay on the principle of population (1798) de Malthus contribuiu para a estruturação lógica da teoria da selecção natural? Poder-se-á afirmar, sem reservas, que o princípio malthusiano da população serviu de fundamento à ideia de luta pela vida nos reinos animal e vegetal?

Darwin estendeu o princípio malthusiano da população a todos os seres viventes na terra ${ }^{92}$, mas o seu quadro problemático é muito distinto do objecto do economista inglês, Thomas Malthus. Este cuidou de equacionar o problema do progresso social, da felicidade e da perfectibilidade do homem à luz das dificuldades resultantes do desequilíbrio entre o poder reprodutivo da espécie humana e o poder da terra de produzir alimentos. Segundo os postulados malthusianos: «Primeiro: a comida é necessária à existência do homem. Segundo: a paixão entre os sexos é necessária e manter-se-á aproximadamente no seu estado actual» 93 , conforme a regra de todos os tempos, pois, acrescenta Malthus, «no sentido da extinção da paixão entre os sexos, ainda não se registou o mínimo progresso. Parece existir com tanta intensidade no presente como há dois ou quatro mil anos» ${ }^{94}$, donde resulta que «o poder da população

Lisboa, Ediçōes 70, s. d., sobretudo pp. 11-42; Pietro Redondi, «Sciences». In: André Burguière, Dictionnaire des sciences historiques, Paris, Presses Universitaires de France, 1986, pp. 623-630.

88 Vide: Gertrude Himmelfarb, Darwin and the darwinian revolution, ob. cit., p. 10.

${ }^{89}$ Vide, entre outros, Alberto Candeias, A vida e a obra de Darwin, Lisboa, Cosmos, 1941, sobretudo pp. 5-37. Anna Sproule, Charles Darwin. A importância da teoria da evolução de Darwin na compreensão do mundo biológico, Lisboa, Editora Replicação, 1991, p. 15 e ss.; Jonathan Howard, Darwin, Lisboa, Publicações Dom Quixote, 1982, p. 17 e ss.; Giuseppe Montalenti, Charles Darwin, Lisboa, Edições 70, 1984, pp. 9-19.

${ }^{90}$ Vide: Syluan S. Schweber, «Facteurs idéologiques et intellectuels dans la genèse de la théorie de la sélection naturelle». In: De Darwin au darwinisme: science et idéologie. Congrès International pour le Centenaire de la mort de Darwin. Paris-Chantilly 13-16 Septembre 1982. Édition préparée par Yvette Conry. Paris, Librairie Philosophique J. Vrin, 1983, sobretudo p. 130 e ss.

91 Vide: Michael T. Ghiselin, «Darwin, Charles Robert 1809-1882». In: Dictionnaire du darwinisme et de l'évolution, vol. 1, ob. cit., pp. 777-778.

92 Vide: Pierre Lantz, "Malthus-Sismondi-Darwin. Populations et concurrence vitale», Les Études Philosophiques, Paris, 3, Jul.-Set. 1984, pp. 385-398.

93 Thomas Robert Malthus, Ensaio sobre o princípio da população, Trad. Eduardo Saló, Mem Martins, Europa-América, s. d., p. 26.

${ }^{9}$ Idem, ibidem. 
é infinitamente maior que o da Terra para produzir a subsistência do homem» ${ }^{95}$. Essa diferença de grandeza é matematizada na célebre fórmula do princípio malthusiano da população: «a população, quando não controlada, aumenta em razão geométrica, enquanto a subsistência aumenta apenas em razão aritmética» 96 .

Ora, enquanto Malthus era um pastor anglicano e um reformista social ${ }^{97}$, defensor do voluntarismo moral (moral restraint), Darwin era um investigador, por conta própria e a tempo inteiro, da economia da natureza, empenhado na construção da lógica evolucionária da vida. As referências que Darwin faz nas suas obras capitais ao princípio malthusiano da população também não implicam a fundamentação teológica que Malthus atribuiu ao seu princípio, nem as medidas de controlo demográfico propostas pelo reverendo ${ }^{98}$. Assim sendo, será absolutamente seguro afirmar que o ensaio malthusiano exerceu a função de "catalisador»" 99 da teoria evolucionária por selecção natural concebida ao mesmo tempo mas, independentemente, por Darwin e Wallace? ${ }^{100}$

É bem sabido que Darwin conta na sua Autobiografia, escrita em 1876, que, após a viagem à volta do mundo a bordo do Beagle (1831-1836), começou a desenvolver um trabalho imenso de ordenação de todos os factos de algum modo relativos às variações dos animais e das plantas, quer em estado doméstico, quer em estado de liberdade selvagem e que não tardou a compreender que «la selección era la clave del éxito que ha encontrado el hombre para crear razas útiles de animales y de plantas» ${ }^{101}$.

95 Idem, ibidem.

96 Idem, ibidem.

97 Malthus era membro do partido Whig. Vide: William Peterson, «La postérité de Malthus». In: Malthus, le premier anti-malthusien, Paris, Dunod-Bordas, 1980, pp. 230-235.

98 Vide: Paul Crook, Darwinism, war and history, Cambridge, University Press, 1994, p. 17 e ss.

99 Termo de William Peterson, «La postérité de Malthus», art. cit., p. 213 e ss.

100 Veja-se o testemunho do próprio A. R. Wallace: «both Darwin and myself, at the critical period when our minds were freshly stored with a considerable body of personal observation and reflection bearing upon the problem to be solved, had our attention directed to the system of positive checks as expounded by Malthus in his 'Principles of Population'. The effect of this was analogous to that of friction upon the specially-prepared match, producing that flash of insight which led us immediately to the simple but universal law of the 'survival of the fittest', as the longsought effective cause of the continuous modification and adaptation of living things", The Darwin-Wallace celebration held on thursday, 1st July, 1908, ob. cit., p. 9. É de notar que esta obra comemorativa do quinquagésimo aniversário da comunicação conjunta de Charles Darwin e Alfred Russel Wallace, "On the Tendency of Species to form Varieties; and on the Perpetuation of Varieties and Species by Natural Means of Selection», inclui uma selecção de textos do Essay de Malthus feita e apresentada por Wallace na cerimónia. Em seu entender, aquelas passagens da obra malthusiana teriam sugerido tanto a ele próprio como a Darwin a ideia de selecção natural. Vide: The Darwin-Wallace celebration held on thursday, 1st July, 1908, ob. cit., pp. 111-118. Este documento que está esquecido é do maior interesse para uma abordagem epistemológica da génese da teoria científica em causa. Atente-se, no entanto, que, já em 1858, Wallace e Darwin não sustentavam rigorosamente o mesmo modelo. Sobre este assunto, vide, entre outros, Georges Canguilhem, "Charles Darwin. I. - Les concepts de 'lutte pour l'existence' et de 'selection naturelle' en 1858: Charles Darwin et Alfred Russel Wallace». In: Études d'histoire et de philosophie des sciences. Troisième édition. Paris, Librairie Philosophique J. Vrin, 1975, pp. 99-111.

101 Charles Darwin, Memorias y epistolario intimo... ob. cit., p. 81. 
Mas, via-se confrontado com um problema: «cómo podía ser aplicada la selección a organismos vivientes en estado natural? He aquí lo que constituyó para mí un misterio durante algún tiempo. En octubre de 1838, es decir quince meses después de comenzada mi encuesta sistemática, me acaeció leer sólo por vía de entretenimiento, el libro de Malthus sobre la Población. Yo estaba bien preparado, por haber observado prolongada y continuamente los hábitos de los animales y de las plantas, para apreciar la lucha por la existencia que se encuentra en todas partes; y entonces se me ocurrió la idea de que en tales circunstancias, las variaciones favorables tenderían a ser preservadas, mientras otras menos felices serían destruídas» ${ }^{102}$. Ressalta desta exposição darwiniana da génese da sua teoria que o princípio malthusiano da população substancializa a causa da luta pela existência, mas não explica a sobrevivência de uns indivíduos e a eliminação de outros, nada adianta quanto à problemática da descendência com modificaçôes das espécies, que Darwin procurava equacionar a partir da noção de luta, mas também das noções igualmente capitais de variação e de selecção.

Por isso, perguntamos: a leitura da obra de Malthus terá contribuído de modo significativo para a formulação científica da sua hipótese capital? Deverá o epistemólogo limitar-se a reproduzir a explicação que o próprio Darwin deu ${ }^{103}$ sobre o nascimento da sua teoria?

Por outro lado, a referência que Darwin fez ao ensaio malthusiano na Origem das espécies ${ }^{104}$ estabelece um vínculo lógico entre o princípio da população e o princípio da luta pela vida, válido para todas as espécies. Mas, para se demarcar da inspiração malthusiana, Darwin sublinha que o princípio da população se aplica com mais intensidade ao mundo animal e vegetal do que à espécie humana. É que, no caso das plantas e dos animais, em estado de natureza, textualmente, «there can be no artificial increase of food no prudential restraint from marriage» ${ }^{105}$. No entanto, esta nota não significava qualquer reserva darwiniana quanto à aplicação da teoria da luta e da selecção à espécie humana.

Assim, em The descent of man (1871) no capítulo II «On the manner of development of man from some lower form», Darwin, ao tratar o tópico «rate of increase», remete o leitor para a obra malthusiana ${ }^{106}$. Em termos de estratégia epistemológica é de sublinhar que o tópico «rate of increase» é precedido pela problemática da variabilidade do corpo e do espírito do homem, da variação e das suas leis no homem e nos animais inferiores, da acção directa das condições existenciais, dos efeitos do uso das partes, enfim da questão crucial da hereditariedade; e, é sucedido pelo tópico da selecção natural. Situada entre o problema da variação e a defesa da hipótese da selecção natural, enquanto mecanismo evolucionário, a abordagem do crescimento demográfico à luz do princípio malthusiano serve, apenas, para justificar a inevitabilidade da luta pela existência.

\footnotetext{
102 Idem, ibidem.

103 Sobre a pertinência desta questão vide Georges Canguilhem, Ideologia e racionalidade nas ciências da vida, ob. cit., p. 18 e ss.

104 Vide: Charles Darwin, The origin of species... Sixth edition, ob. cit., p. 50.

105 Idem, ibidem.

106 Charles Darwin, The descent of man, and selection in relation to sex, ob. cit., p. 44, nota 57: "See the ever memorable 'Essay on the Principle of Population ', by the Rev. T. Malthus».
} 
Tanto na obra The descent of man como em The origin of species ${ }^{107}$, a lógica argumentativa é a mesma: da variação para a luta e da luta para a selecção. É no momento da luta que o princípio da população funciona e parece-nos que Darwin o valoriza porque ele se inscreve no quadro do modelo matemático de cientificidade que era justamente um modelo bastante creditado na época.

Darwin refere-se também ao princípio da população na obra The variation of animals and plants under domestication (1868) ${ }^{108}$ a propósito da fauna e da flora do arquipélago das Galápagos e, de novo, se constata que a taxa geométrica de crescimento intraespecífico, necessariamente, determina a luta pelo alimento, pelo território e pela reprodução.

Em suma: na teoria darwiniana, as espécies animais e vegetais reproduzem-se tão rápida e abundantemente ${ }^{109}$ que a luta pela vida é inevitável: luta entre indivíduos da mesma espécie, luta entre indivíduos de espécies diferentes e luta com as condiçôes físicas da vida. É o poder de multiplicação das espécies que gera a luta donde resulta a sobrevivência dos mais aptos e a eliminação dos menos aptos, ou seja, a selecção natural das variações vantajosas e consequentemente a evolução adaptativa. A luta é fundamental mas a matéria prima sobre a qual opera a selecção natural é a variação.

À luz do exposto, parece-nos ser algo controverso que a leitura do ensaio malthusiano tenha sido a fonte inspiradora da articulação lógica entre variação, luta e selecção natural, embora tenha permitido fundamentar a ideia de luta no princípio da população. Mas, mesmo que se admita essa versão do nascimento da teoria darwiniana, será defensável que Darwin se limitou a transferir o espírito de competição reinante na economia política britânica (Adam Smith, Malthus, Ricardo) para a biologia? Será esta leitura sociologista da teoria darwiniana aquela que melhor dá conta do êxito da Origem das espécies?

Seguramente, as razōes contextuais, biográficas e científicas, culturais e economicosociais, não esgotam o assunto. Ilse Bulhof ${ }^{110}$ procurou a chave do sucesso da obra na sua dimensão literária e verificou que a Origem das espécies está escrita num excepcional estilo literário-retórico-poético. Quer isto dizer que a obra apresenta estratégias de comunicação, quer dos argumentos lógicos, quer das experiências sistemáticas, que não se situam no plano estritamente informativo. De facto, a obra é uma pesquisa da validade da hipótese da selecção natural frente a um imenso caudal de factos da natureza, e nessa busca há uma espécie de dança contínua entre argumentos e contra-argumentos, a qual imprime à sua hipótese uma vigorosa força persuasiva.

107 Atente-se na sequência dos capítulos da obra The origin of species: «I- Variation under Domestication; II- Variation under Nature; III- Struggle for Existence; IV- Natural Selection; or the Survival of the Fittest», Sixth edition, ob. cit., pp. V-VI.

108 Vide: Charles Darwin, The variation of animals and plants under domestication, vol. 1, ob. cit., p. 10 .

${ }^{109}$ No impressivo texto darwiniano: «all organic beings, without exception, tend to increase at so high a ratio, that no district, no station, not even the whole surface of the land or the whole ocean, would hold the progeny of a single pair after a certain number of generations», Idem, ibidem, vol. 1, pp. 5-6.

110 Vide: Ilse N. Bulhof, The language of science. A study of the Relationship between literature and science in the perspective of a hermeneutical ontology with a case study of Darwin's The origin of species, Leiden, E.J. Brill, 1992. 
Darwin, ora defende e logo ataca a sua hipótese e esse jogo argumentativo, que se salda na reivindicação do carácter científico da sua hipótese ${ }^{111}$, desenrola-se num estilo literário ímpar. Por isso, Ilse Bulhof concluiu que «Darwin's principal sucess was due to his performance as a writer» ${ }^{112}$. Sem dúvida, a obra agarra o leitor, sem dúvida essa qualidade deve ser tida em conta e até arriscamos pensar que Darwin terá desenvolvido a sua tendência para escrever bem no curso de teologia em Cambridge entre 1828 e 1831.

Por outro lado, importa ter sempre presente que a obra darwiniana defendia uma hipótese inovadora, que demorou cerca de vinte anos ${ }^{113}$ a ser testada e convertida em modelo teórico, grosso modo entre 1837 e 1859. Era normal que ela despertasse o interesse da comunidade científica e a curiosidade do público leitor. François Russo admite que nada há de extraordinário no sucesso da obra darwiniana pois uma revolução científica, ou «le saut dans la nouveauté est souvent offert par une publication qui fait sensation" ${ }^{114}$. A Origem das espécies não é uma excepção à regra ${ }^{115}$. Também ela teve um longo tempo de maturação para poder dar «o salto na novidade» de que fala François Russo. Darwin contava trinta anos quando começou a conceber a teoria da descendência com modificaçôes por selecção natural. Aos cinquenta anos de idade dá à estampa a sua obra magna que se difundiu por todo o mundo em onze línguas até à morte de Darwin em 1882, e num total de vinte e nove línguas até $1977^{116}$. Outras obras de Darwin, especialmente A Origem do homem(1871) e A expressão das emoções (1872), obras que desenvolvem o «longo argumento» de $1859^{117}$, particularmente em relação à espécie humana, ficaram um pouco aquém da Origem das espécies.

Desde os primeiros anos da década de sessenta do século XIX, a teoria darwiniana foi difundida por Thomas H. Huxley e A. Russel Wallace sob a denominação de darwinismo ${ }^{118}$. Mas, não havia, de facto, uma identidade teorética absoluta entre as versôes daqueles cientistas e, menos ainda, entre cada uma delas e a teoria darwiniana.

111 Vide, por exemplo, Charles Darwin, The variation of animals and plants under domestication, vol. 1, ob. cit., p. 8 e ss.

112 Ilse N. Bulhof The language of science... ob. cit., p. 89.

113 Vinte anos é o tempo médio de maturação das grandes obras científicas e filosóficas. Vide: Paul Scheurer, Révolutions de la science et permanence du réel, ob. cit., sobretudo p. 7.

${ }^{114}$ François Russo, Nature et méthode de l'histoire de sciences, Paris, Librairie Scientifique et Technique Albert Blanchard, 1983, p. 99.

$115 \mathrm{Na}$ história das ciências, algumas obras são marcos de viragem, sinalizam a emergência de novos paradigmas: "par exemple la publication des 'Principia' de Newton en 1687, de l' 'Origine des espèces' en 1859 par Darwin, de la Communication à l’Académie de Berlin en Décembre 1900 de Planck qui introduisait la notion de quanta, du mémoire d'Einstein en 1905 sur la relativité», François Russo, Nature et méthode de l'histoire de sciences, ob. cit., p. 99.

116 Vide: R. B. Freeman, The works of Charles Darwin. An annotated bibliographical handlist, ob. cit., p. 83.

117 Vide: Charles Darwin, The descent of man, and selection in relation to sex, ob. cit., pp. 1-4; Idem, The expression of the emotions in man and animals. With a preface by Konrad Lorenz. Chicago-London, The University of Chicago Press, 1965, sobretudo, pp. 347-366.

118 Vide: Ernst Mayr, Darwin et la pensée moderne de l'évolution. Traduit de l'anglais (États-Unis) par René Lambert. Paris, Éditions Odile Jacob, 1993, p. 117. 
Thomas Huxley não aceitava o princípio da selecção natural, enquanto Wallace não o aplicava à evolução da espécie humana ${ }^{119}$. De qualquer modo, o princípio da descendência das espécies a partir de um antepassado comum, segundo um processo de divergência, ligava a teoria darwiniana às múltiplas e heterogéneas versões, designadamente de Th. Huxley, Wallace, Lyell, Hooker, Asa Gray, Fritz Müller e E. Hæckel ${ }^{120}$. Pode, então, afirmar-se que a ideia de evolução por meios naturais era uma constante no chamado darwinismo. Para além deste enunciado, entramos no terreno das incompatibilidades e, se bem compreendemos, é esta a razão que justifica a ausência de um verbete intitulado simplesmente darwinismo no monumental Dictionnaire du darwinisme et de l'évolution. O que encontramos no referido dicionário é um conjunto de múltiplos darwinismos ${ }^{121}$ em que cada darwinista é um caso.

De facto, a conclusão que se retira de estudos já efectuados sobre o darwinismo, em diversas comunidades científicas, pode resumir-se neste enunciado: «in pratica, Homo Darwinianus è una specie politipica» ${ }^{122}$. No mesmo sentido, o especialista Jean Gayon faz esta advertência: "Tout historien dont l'intention serait d'embrasser la totalité des manifestations historiques du 'darwinisme' devrait d'abord faire face à l'extrême hétérogénéité de celles-ci» ${ }^{123}$. Depois de ter estudado muitas fontes portuguesas, podemos acrescentar o seguinte: todo o historiador que tome como ponto de partida uma definição ideal de darwinismo, identificado com a teoria de Darwin, chega necessariamente a resultados perturbadores. Em nosso entender, foi o que aconteceu na análise que Yvette Conry fez do darwinismo francês. A sua definição de darwinismo ${ }^{124}$ comporta e articula todos os elementos capitais da teoria darwiniana e, por isso mesmo, no final do seu excelente trabalho, Yvette Conry teve de concluir que, até ao final do século XIX, o darwinismo não foi introduzido em França: «nous déclarons avoir vainement cherché un darwiniste» 125 .

Sem perder de vista a definição ideal de darwinismo, parece-nos ser legítimo adoptar um critério menos radical, atendendo à flexibilidade relativa da própria teoria darwiniana. Julgamos que essa flexibilidade resultou de dificuldades interiores à

119 Vide: Idem, ibidem, p. 127 e ss. Daniel Becquemont, Darwin, darwinisme, évolutionnisme, ob. cit., p. 193 e ss.

120 Vide: Ernst Mayr, Darwin et la pensée moderne de l'évolution, ob. cit., p. 127 e ss.

121 O referido dicionário trata os seguintes darwinismos: alemão, anglo-saxónico, árabe, cubano, espanhol, francês, italiano, japonês, nórdico, russo, tendo como autores, respectivamente, Britta RuppEisenreich, Mario di Gregorio, Mohammed Allal Sinaceur, Pedro M. Pruna, Diego Núñez, Gérard Molina, Giovanni Landucci, Britta Rupp-Eisenreich, Philippe Janvier, Vasilij Babkov. Vide: Dictionnaire du darwinisme et de l'évolution, vol. 1, ob. cit., pp. 822-1108.

122 Antonello La Vergata, "Che rivoluzione fu la rivoluzione darwiniana?», art. cit., p. 105.

123 Jean Gayon, Darwin et l'après-Darwin. Une histoire de l'hypothèse de sélection naturelle, Paris, Éditions Kimé, 1992, p. 4.

124 Segundo Yvette Conry: «le darwinisme est une étiologie de l'évolution (en quoi il intègre une doctrine de la spéciacion) à partir d'une problématique de l'adaptation, par la norme conceptuelle de la sélection (qui engage un contexte écologique) et le présupposé de la variation", L’introduction du darwinisme en France au XIX $X^{e}$ siècle, Paris, Librairie Philosophique J. Vrin, 1974, p. 425.

125 Idem, ibidem. 
teoria da selecção natural, mas também do interesse de Darwin em que a sua teoria fosse secundada por um número crescente de cientistas.

O problema interno fundamental residia no desconhecimento das leis da hereditariedade, o que foi inteiramente assumido por Darwin, desde a primeira edição da Origem das espécies: "the laws governing inheritance are quite unknown» ${ }^{126}$. Ora, se o problema das variações e da sua transmissão à descendência não estava resolvido, é óbvio que, tratando-se de um pré-requisito da selecção natural, esta apresentava alguma fragilidade. Ou, em termos mais simples: como pensar a selecção natural sem conhecer as leis da hereditariedade, já que estas encerram a chave do mecanismo da descendência com modificações? Sem uma ciência experimental da variação e da hereditariedade ${ }^{127}$, como fundar a hipótese da selecção natural?

Não seria lógico que a comunidade científica oferecesse alguma resistência à selecção natural e, ignorando a distinção elementar entre soma e germen ${ }^{128}$, recuperasse o princípio lamarckiano da hereditariedade dos caracteres adquiridos que, de modo algum, punha em causa o fundamental, isto é, a evolução por vias naturais? É perfeitamente compreensível que até às décadas de trinta e de quarenta do século XX, o darwinismo não apresente como característica fixa a selecção natural ${ }^{129}$, embora esta constituísse o núcleo duro ${ }^{130}$ da teoria darwiniana. De resto, o próprio Darwin, sem jamais abdicar da selecção natural das variaçóes úteis, em termos de adaptação ao meio, teve necessidade de construir uma teoria provisória da hereditariedade, na qual, justamente, incorpora alguns factores lamarckianos, como a acção directa do meio (alimentação, clima, etc.) e a actividade do organismo (uso ou não uso dos órgãos) na origem das variaçôes transmissíveis à descendência.

É que, das numerosas críticas feitas na década de sessenta do século XIX à Origem das espécies, algumas incidiam especialmente sobre a questão das variaçōes e da sua transmissão ${ }^{131}$ e, por isso, não admira que, em 1868, Darwin desenvolva e torne

126 Charles Darwin, On the origin of species... (A reprint of the first editon), ob. cit., p. 11; na edição definitiva, escreve: "the laws governing inheritance are for the most part unknown", The origin of species... Sixth edition, ob. cit., p. 10.

127 Recorde-se que, praticamente, só a partir de 1920, com a genética das populações, na sequência da redescoberta de Mendel em 1900, se começa a formular a teoria matemática da selecção natural. É a genética das populaçôes que vem construir o campo conceptual adequado e os meios de controlo experimental da hipótese da selecção natural. Vide: Jean Gayon, Darwin et l'après-Darwin. Une histoire de l'hypothèse de sélection naturelle, ob. cit., p. 334 e ss.

128 Como é sabido, a separação entre germen e soma foi introduzida por Weismann entre 1883 e 1892 , na sua teoria do plasma germinativo que vibrou um golpe muito duro no princípio lamarckiano da hereditariedade dos caracteres adquiridos. Se as variaçôes do organismo (o soma) não produzem efeitos sobre o germen, é lógico que a hereditariedade do adquirido é insustentável. Vide: Charles Lenay, La découverte des lois de l'hérédité (1862-1900). Une anthologie, s.l., Presses Pocket, 1990, p. 163 e ss.

129 Vide: Ernst Mayr, Una larga controversia: Darwin y el darwinismo, Barcelona, Crítica, 1992, p. 143 e ss.

130 Vide: Ernst Mayr, Darwin et la pensée moderne de l'évolution, ob. cit., p. 117 e ss.

${ }^{131}$ É de salientar a crítica de Fleeming Jenkin feita em 1867. O autor observava que as variaçóes, mesmo muito vantajosas, se diluiriam na descendência pois, à luz da crença generalizada na hereditariedade por mistura, cada novo indivíduo apresentaria caracteres intermédios relativamente aos seus progenitores. Vide: Jean Gayon, Darwin et l'après-Darwin. Une histoire de l'hypothèse de sélection naturelle, ob. cit., pp. 95-112. 
pública a sua hipótese da pangénese, na obra The variation of animals and plants under domestication. Em termos muito sumários, Darwin supõe que todas as células do corpo, em todas as etapas da vida, produzem gémulas que percorrem todo o corpo e se reúnem às células sexuais. Ora, sob a influência do meio e da actividade do organismo, as células podiam sofrer alterações e transmitir essas alterações às gémulas que, por seu turno, as comunicavam às células sexuais e estas transmitiam-nas à descendência ${ }^{132}$.

Admitir a hereditariedade dos caracteres adquiridos pelo soma, sob a acção directa do meio e do uso ou não uso dos órgãos, equivalia a aceitar o mecanismo transformista lamarckiano, embora sem renunciar ao estatuto que, desde 1859, atruibuia à selecção natural. A permeabilidade da teoria darwiniana aos factores lamarckianos é também notória na edição definitiva da Origem das espécies. Ao resumir o volume, Darwin escreveu: «(...) species have been modified, during a long course of descent. This has been effected chiefly through the natural selection of numerous successive, slight, favourable variations; aided in an important manner by the inherited effects of the use and disuse of parts; and (...) by the direct action of external conditions(...)»133. Nas palavras de Darwin, a selecção natural continua a ser o mecanismo chave da evolução, mas não é o único mecanismo. Sabe-se bem que a questão da hereditariedade era o calcanhar de Aquiles de Darwin e por isso o historiador compreende e relativiza as referências de tipo lamarckiano. Mas o historiador também constata que muitos cientistas acabaram por valorizar excessivamente os factores lamarckianos, tendo mesmo excluído a selecção natural das suas versões da transformação das espécies. Os mecanismos evolutivos que defendiam tinham um carácter rigorosamente natural, mas sem a selecção natural estavam longe do autêntico darwinismo darwiniano. Só no século XX, depois da genética e com a síntese evolutiva moderna é que o paradigma darwiniano da história natural começou a revelar todo o seu (aparentemente inesgotável) poder epistemológico.

132 Vide: Charles Darwin, «Provisional hypothesis of pangenesis», The variation of animals and plants under domestication, vol. 2, ob. cit., pp. 349-399.

133 Charles Darwin, The origin of species... Sixth edition, ob. cit., p. 421. Darwin reafirma a não exclusividade da selecção natural na obra The descent of man, and selection in relation to sex, ob. cit., por exemplo, p. 61. 

Série

Documentos

Imprensa da Universidade de Coimbra

Coimbra University Press

2010

- U

C • 